\title{
State of the Journal Report
}

\author{
G. Roberts ${ }^{1}$, Editor-in-Chief; A. Harder ${ }^{2}$, Senior Editor; J. Lindner ${ }^{3}$, Senior Editor
}

Advancements in Agricultural Development $(A A D)$ was started to address a need for a scholarly journal focused on the practical outcomes of research in agricultural development research. We have just concluded our second year of operation at $A A D$ and want to share some reflections on the past and goals for the future. We wish to thank the authors and reviewers who have contributed to $A A D$ over this time (see the reviewer list at the end of this report). We also wish to acknowledge and thank the Department of Curriculum and Teaching at Auburn University for their financial support of $A A D$. We also wish to thank our editorial assistants (Katrina Alford, Olivia Caillouet, Andy Chaparro, \& Alexandria McLeod) who work behind the scenes to make things run smoothly.

\section{Articles and Authorship}

Issues in agriculture are often time-sensitive, so we sought from the beginning of $A A D$ to develop a timely review/publication process to allow quicker dissemination of research. The number of published articles in AAD has slightly increased while the number of submissions is increasing (see Table 1). We anticipate a $25 \%$ increase in the number of published articles in 2022. Consequently, we will be adding a fourth issue beginning in Volume 3 . We have also recently recruited Dr. Robert Strong from Texas A\&M University as an Editor to assist with the review process, who brings prior experience as the Executive Editor of the Journal of International Agricultural and Extension Education to the $A A D$ team. The breadth of contributing authors to $A A D$ continues to expand. For Volumes 1 and 2 (50 articles), there were 135 unique authors from 33 universities and 5 countries.

\section{Table 1}

Published Articles in AAD

\begin{tabular}{lcc}
\hline Volume (Year) & Issue & Number of articles published \\
\hline $1(2020)$ & 1 & 8 \\
& 2 & 7 \\
$2(2021)$ & 3 & 8 \\
& 1 & 8 \\
& 2 & 10 \\
& 3 & 9 \\
\hline
\end{tabular}

1. Grady Roberts, University of Florida, 220 Rolfs Hall, PO Box 110540, Gainesville, FL 32611 groberts@ufl.edu, iD https://orcid.org/0000-0001-7618-7850

2. Amy Harder, University of Florida 117B Bryant Hall, PO Box 112060, Gainesville, FL 32611, amharder@ufl.edu, iD https://orcid.org/0000-0002-7042-2028

3. Jimmy Lindner, Auburn University, 5058 Haley Center, Auburn, AL 36849, jrl0039@auburn.edu, (iD) https://orcid.org/0000-0002-1448-3846 


\section{Consumption and Usage}

The number of people consuming research published in $A A D$ is expanding. The number of views for articles has been trending upwards (see Figure 1). The number of citations for articles in $A A D$ is also increasing. The Cited By and Plum $X$ Analytics features we installed on our web platform allow authors see how their research is being used. To further expand how research published in $A A D$ is disseminated, we have launched Facebook (@agdevresearch) and Twitter (@agdevresearch) accounts to announce newly published research and to highlight previous research published in $A A D$.

\section{Figure 1}

\section{Article Views in $A A D$}

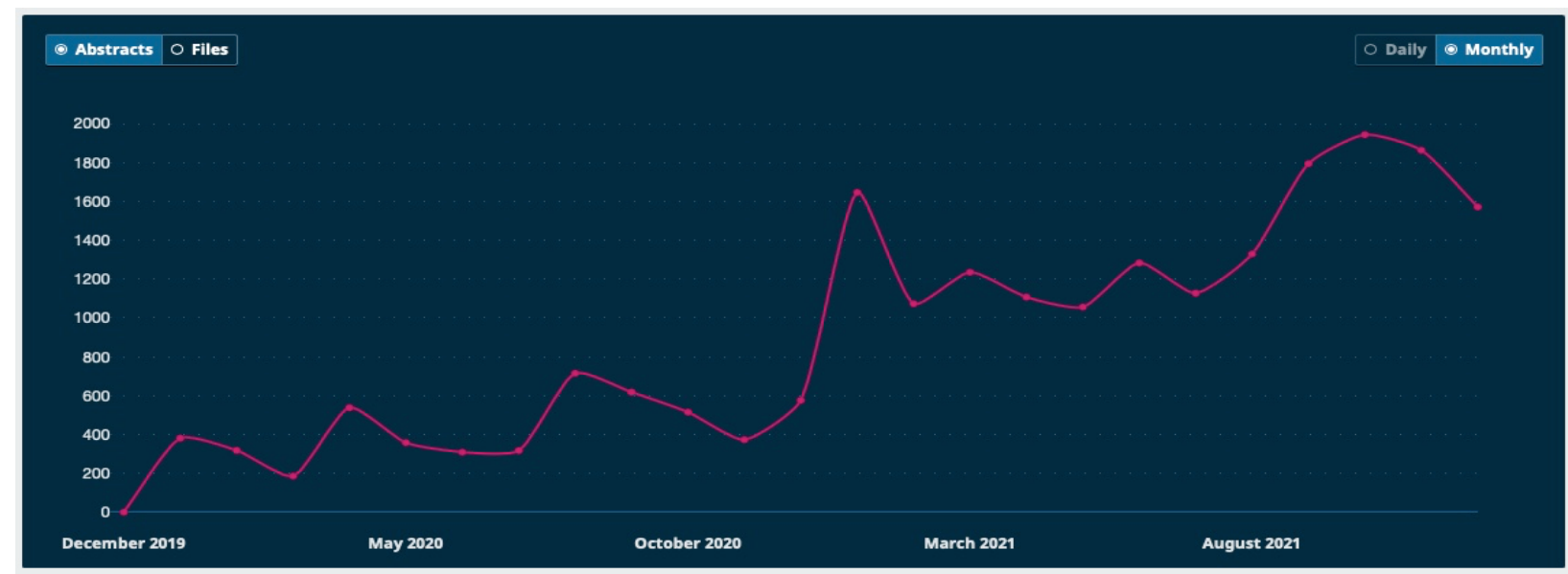

\section{Metadata and Indexing}

We are continually working to make research in $A A D$ more discoverable by the larger scientific community. We submit the complete metadata to Crossref, which includes the full abstract, references, and funding information for each article. Including the references means that articles published in $A A D$ are linked with the articles they cited and will show up in the cited by sections on other publisher's pages.

Indexing is an important part of making research in $A A D$ even more discoverable. $A A D$ is currently indexed in the Directory of Open Access Journals (DOAJ), Google Scholar, ROAD, and Ulrichs. Our goal is to be indexed in Scopus and the Web of Science, both of which require a documented history of the impacts of the journal. We proactively taking steps to position $A A D$ for inclusion in these prestigious indices to increase visibility of research published in $A A D$. 


\section{Looking Ahead}

The editorial team at $A A D$ continually works to meet the needs of researchers in our field. As we look into 2022 and beyond, our goals are to:

1. continually refine our editorial process to meet researcher needs;

2. attract research from the global agricultural development community;

3. add features to our web-platform to enhance the author and reader experience; and

4. position $A A D$ for inclusion in Scopus and the Web of Science.

\section{0 and 2021 Reviewers}

David Agole, Kyambogo University, Uganda

Lauri Baker, University of Florida, USA

Matt Baker, Texas A\&M University, USA

Anna Ball, University of Illinois, USA

Mark Balschweid, University of Nebraska-Lincoln, USA

Debra Barry, University of Florida, USA

Matt Benge, University of Florida, USA

Amanda Bowling, The Ohio State University, USA

Gary Briers, Texas A\&M University, USA

Amy Brown, University of Florida, USA

James Bunch, University of Florida, USA

Chris Clemons, Auburn University, USA

Nathan Conner, University of Nebraska-Lincoln, USA

Marina D'Abreau Denny, Mississippi State University, USA

John Diaz, University of Florida, USA

David Doerfert, Texas Tech University, USA

Kim Dooley, Texas A\&M University, USA

Christopher Eck, Clemson University, USA

Craig Edwards, Oklahoma State University, USA

Nick Fuhrman, University of Georgia, USA

Raphael Gikunda, Chuka University, Kenya

Erin Gorter, California Polytechnic State University, USA

Carla Jagger, University of Florida, USA

Jay Jayaratne, North Carolina State University, USA

Donald Johnson, University of Arkansas, USA

Kathleen Kelsey, University of Florida, USA

James Kinsella, University College Dublin, Ireland

Neil Knobloch, Purdue University, USA

Vikram Koundinya, University of California, Davis, USA
Alexa Lamm, University of Georgia, USA Angela Lindsey, University of Florida, USA Jamie Loizzo, University of Florida, USA Juma Magogo, Texas Tech University, USA Adam Marx, North Dakota State University Robert McKendree, Michigan State University Jason McKibben, Auburn University, USA Aaron McKim, Michigan State University, USA Ashley McLeod-Morin, University of Florida, USA Brian Myers, University of Florida, USA Lendel Narine, Utah State University, USA Jera Niewoehner-Green, The Ohio State University, USA Jason Peake, University of Georgia, USA Absalon Pierre, University of Florida, USA Shelli Rampold, University of Florida, USA Matt Raven, Michigan State University, USA Bryan Reiling, University of Nebraska-Lincoln, USA Richie Roberts, Louisiana State University, USA Mary Rodriguez, The Ohio State University, USA Taylor Ruth, University of Nebraska-Lincoln, USA Scott Scheer, The Ohio State University, USA Tyson J. Sorensen, Utah State University, USA Matthew Sowcik, University of Florida, USA Stacey Stearns, University of Connecticut, USA Nicole Stedman, University of Florida, USA Carrie Stephens, The University of Tennessee, USA Christopher Stripling, The University of Tennessee, USA Jennifer Strong, Texas A\&M University, USA Ricky Telg, University of Florida, USA

(C) 2022 by authors. This article is an open access article distributed under the terms and conditions of the Creative Commons Attribution license (http://creativecommons.org/licenses/by/4.0/). 